\title{
PENSAMENTO CIENTÍFICO MODERNO E ABALO À ESFERA PÚBLICA: UMA REFLEXÃO COM BASE EM HANNAH ARENDT
}

\author{
Claudio Ricardo Martins dos Reis ${ }^{1}$ \\ Universidade Federal do Rio Grande do Sul (UFRGS) \\ https://orcid.org/0000-0002-4214-530X
}

\section{RESUMO:}

Este trabalho tem por objetivo refletir sobre a emergência da modernidade, a consolidação do pensamento científico moderno e suas consequências especificamente indesejáveis no domínio da política. Para isso, baseio-me no pensamento de Hannah Arendt. Arendt destaca três eventos como os principais precursores da era moderna: a exploração dos continentes, a Reforma e a invenção e utilização do telescópio. Discuto brevemente a relação desses eventos com a alienação do mundo, tal como entendida por Arendt, e me aprofundo nas novidades relativas à ciência. Menciono Galileu e a revolução copernicana, o método experimental e quantitativo, o papel da fabricação de instrumentos na produção do conhecimento, o critério avaliativo de sucesso prático e o raciocínio lógico-matemático como elementos que passam a moldar a atividade científica. A partir daí, destaco a tendência, descrita por Arendt, do pensamento científico moderno em abarcar os mais diversos campos da vida cotidiana, especialmente seu âmbito público. Concluo destacando o modo como o pensamento cientificista - que possui características próprias do homo faber mina a possibilidade de ação quando adentra a esfera política. Na medida em que "ser livre e agir é a mesma coisa", impede também a manifestação da liberdade. Mais do que isso, abordo como o cientificismo vai à contramão da pluralidade, da singularidade e da espontaneidade humanas. Os governos totalitários e as sociedades de consumo são exemplos extremos e reais do que a racionalidade do homo faber pode fazer quando substitui o campo da ação. Ao finalizar, destaco um grande desafio que temos pela frente.

PALAVRAS-CHAVE: Ação; Alienação do mundo; Cientificismo; Hannah Arendt; Pluralidade.

\section{MODERN SCIENTIFIC THINKING AND THE SHOCK OF THE PUBLIC SPHERE: A REFLECTION BASED ON HANNAH ARENDT}

\section{ABSTRACT:}

This work aims to reflect on the emergence of modernity, the consolidation of modern scientific thinking and its specifically undesirable political consequences. For that, I rely on the thought of Hannah Arendt. Arendt highlights three events as the main precursors of the modern era: the "discovery" of the continents, the Reformation, and the invention and use of the telescope. I briefly discuss the relation of these events to the alienation from the world, as understood by Arendt, and delve into the novelties of science. Here I mention Galileo and the Copernican revolution, the experimental and quantitative method, the role of instrument manufacturing in the production of knowledge, the evaluation criterion of practical success, and logicalmathematical reasoning as elements that begin to shape scientific activity. From there, I highlight the movement, as described by Arendt, of modern scientific thought to encompass the most diverse fields of daily life, especially in the public sphere. I conclude highlighting the way in which scientism - which has homo faber's characteristics - undermines the possibility of action when it enters the political sphere. Because "to be free and to act are the same", it also prevents the manifestation of freedom. Moreover, I approach how scientism goes against human plurality, singularity and spontaneity. Totalitarian governments and consumer societies are extreme and real examples of what homo faber's logic can do when it replaces the field of action. At the end, I highlight a great challenge that we need to face.

KEYWORDS: Action; Alienation from the world; Scientism; Hannah Arendt; Plurality.

\footnotetext{
${ }^{1}$ Doutorando em Filosofia na Universidade Federal do Rio Grande do Sul (UFRGS), Rio Grande do Sul Brasil. Bolsista CAPES. E-mail: claudiormreis@gmail.com
}

REIS, Claudio Ricardo Martins dos. Pensamento científico moderno e abalo à esfera pública: uma reflexão com base em Hannah Arendt. Griot : Revista de Filosofia, Amargosa/Bahia, v.17, n.1, p.304-314, junho/2018. 


\section{Introdução}

Hannah Arendt (1906 - 1975) foi uma das mais influentes filósofas políticas do século XX. Foi uma autora singular para o pensamento político ocidental (ver d'Entreves, 2016). Ela própria não se identifica com a tradição majoritária da filosofia política nem da ciência política. De fato, Arendt tem profundas críticas ao modo como esses pensamentos se constituíram.Nessa crítica ela destaca que, desde Platão, a filosofia política busca um conhecimento abstrato que possa reger a vida prática, preocupado prioritariamente em discernir princípios que fundam e legitimam à política. Diferentemente, Arendt procura compreender o modo como o sentido da política se concretiza, ou não, na vida prática. Ela não constrói suas ideias alheia ao que ocorre no mundo empírico. A análise histórica e social atua como fermento e como pano de fundo de todo o seu pensamento. Já no início de A condição humana, principal obra filosófica de Arendt, ela destaca:

O que proponho nas páginas que se seguem é uma reconsideração da condição humana do ponto de vista privilegiado de nossas mais novas experiências e de nossos temores mais recentes. [...] trata-se de pensar o que estamos fazendo. (ARENDT, 2010, p. 6)

Isso não significa, porém, que sua abordagem seja destituída de uma profunda concepção normativa ${ }^{2}$. Por isso ela diverge também da abordagem hegemônica em ciência política, como a da teoria dos sistemas, que se consolidou afastando os aspectos normativos e deixando de lado o que Arendt toma como crucial: o sentido da política. Dessa forma, além de não se adequar à tradição majoritária da filosofia política, a análise de Arendt não se reduz a uma ciência política. Esse pensamento de Arendt deixa explícita grande influência da vertente fenomenalista-existencial.

Neste trabalho, pretendo discutir a reflexão de Hannah Arendt sobre a emergência da modernidade, a consolidação do pensamento científico moderno e suas consequências especificamente indesejáveis no domínio da política ${ }^{3}$; em outras palavras, sobre como a modernidade produziu um cientificismo que invade o âmbito público, enfraquecendo-o e deturpando-o. Para isso, baseio-me principalmente em sua obra $A$ condição humana (Arendt, 2010 [1958]). Meu objetivo neste trabalho não é prioritariamente histórico, mas filosófico, e busca trazer elementos para se pensar a atualidade. Para isso, será necessário, antes, o entendimento sobre como Arendt caracteriza a esfera pública. A partir daí, poderemos nos lançar sobre como uma forma de pensamento que emerge na modernidade se alastra para outros campos, minando o sentido da política. Se esse pensamento

\footnotetext{
${ }^{2}$ Essa afirmação não está livre de controvérsia entre os estudiosos de Hannah Arendt. No entanto, a meu ver, $A$ condição humana é permeada por aspectos normativos. O modo como Arendt caracteriza, por exemplo, a esfera pública traz consigo uma concepção de como a esfera pública deve ser. É isso que lhe permite uma abordagem existencial e histórica que é, ao mesmo tempo, crítica. Aqui cabe uma analogia inusitada com o historiador e filósofo da ciência Thomas Kuhn (1922-1996) e sua obra mais influente, $A$ estrutura das revoluções científicas (Kuhn, 1962). É ainda, em alguma medida, controverso que Kuhn tenha apresentado nesta obra aspectos normativos para a atividade científica. No entanto, a meu ver, o que há de filosoficamente interessante nesse autor é precisamente o fato de que ele retira aspectos prescritivos de sua análise histórica da ciência. Algo muito similar ocorre em Hannah Arendt.

3 A tese não é de que a modernidade e o pensamento científico moderno possuem apenas consequências indesejáveis no domínio da política, nem que possuem consequências lógicas indesejáveis nesse domínio. Trata-se de uma explicação sobre como alguns elementos especificamente modernos do pensamento científico, ao adentrarem a esfera política, deturpam-na (ver nota 4). Para defender essa tese, pressuponho a compreensão de política em Arendt.
}

REIS, Claudio Ricardo Martins dos. Pensamento científico moderno e abalo à esfera pública: uma reflexão com base em Hannah Arendt. Griot : Revista de Filosofia, Amargosa/Bahia, v.17, n.1, p.304-314, junho/2018. 
cientificista se consolida na modernidade, ele não deixou de existir com o período contemporâneo. De fato, nos séculos XX e XXI - com a emergência de governos totalitários e de sociedades de consumo - seus efeitos no âmbito público se tornam ainda mais evidentes.

\section{Esfera pública: pluralidade manifesta na ação, e ação como liberdade}

Antes de refletir sobre a emergência da modernidade, a consolidação do pensamento cientificista e suas consequências para o âmbito público, é importante entender como Hannah Arendt caracteriza a política. Precisamos compreender como ela concebe o político para, então, podermos identificar os efeitos do cientificismo nesse âmbito.

Segundo Arendt, desde Platão, a tradição do pensamento ocidental concebe a política como um campo essencial para a vida, com um caráter funcional associado às necessidades e utilidades do humano. Nessa perspectiva, a política é entendida como meio para algum fim. É por isso que muitas vertentes do pensamento político ocidental a concebem como um "mal necessário". O âmbito político não seria valorizado enquanto tal, mas apenas por contribuir a algo que lhe é alheio. Segundo Arendt, essa é a posição de autores importantes e diversos, tais como Platão, Thomas Hobbes, John Locke e Karl Marx.

Hannah Arendt diverge dessa compreensão do político. Para ela, instrumentalizar a política é deturpar o seu sentido. A política deveria ser entendida como um fim em si mesmo, como a realização da convivência humana de forma livre e autônoma. De acordo com a autora, a política autêntica é realizada por meio da ação, que é precisamente a manifestação de um agente perante outros, em condições de igualdade, por meio das palavras e dos atos. Na medida em que os agentes são singulares e estão num ambiente comum em condições de igualdade, a consequência é de que o domínio público é por excelência plural.

De fato, para Arendt, a condição especificamente humana é aquela da pluralidade, e essa pluralidade pode ser manifesta apenas no âmbito político. Dessa forma, para a autora, é a política quem nos faz humanos. O domínio político deveria ser concebido, portanto, como um domínio próprio e não apenas na sua relação com outros domínios. A política teria, assim, um valor em si mesmo que deveria ser resguardado. Mais do que isso, seria exatamente a esfera pública o que dá sentido às nossas vidas. "Tudo o que os homens fazem, sabem ou experimentam só tem sentido na medida em que se possa falar sobre" (Arendt, 2010, p. 5). Esse "falar sobre" é essencialmente público e constitui um aspecto da ação.

A ação, para Hannah Arendt, é a possibilidade de manifestar essa pluralidade uns aos outros através de múltiplas perspectivas, em contraste com o indivíduo isolado de posse apenas de uma única visão. Estar com os outros, ver e ser visto, falar e ouvir é uma qualidade que não pode ser substituída pelo domínio privado nem por alguma outra conformação do domínio público. Enquanto tal, o domínio público perde seu sentido se se elimina a pluralidade, na medida em que esta é inerente à singularidade humana.

Além da diferença e da pluralidade, o domínio público pressupõe a igualdade: todos são seres humanos e habitam, se movem e constituem um mesmo espaço. Se não deturpada, a esfera pública tem a qualidade de conciliar liberdade e igualdade, pluralidade e espontaneidade. É esse espaço em comum que torna possível a manifestação desses valores e dá sentido às atividades humanas. Portanto, a política autêntica não se encontra

REIS, Claudio Ricardo Martins dos. Pensamento científico moderno e abalo à esfera pública: uma reflexão com base em Hannah Arendt. Griot : Revista de Filosofia, Amargosa/Bahia, v.17, n.1, p.304-314, junho/2018. 
nos indivíduos - nem é um dom de cada pessoa - mas estabelece-se no espaço público enquanto as pessoas agem conjuntamente.

Arendt caracteriza a vita activa a partir de três categorias: trabalho, obra e ação. Em contraste com o trabalho e a obra, presos ao âmbito privado e sendo meios para fins, a ação é o que constitui o âmbito público e é fim em si mesmo, caracterizando o sentido autêntico da política. Isso nos permite afirmar que é na esfera pública que a liberdade se manifesta, pois "ser livre e agir é a mesma coisa" (Arendt, 2005, p. 199). No trabalho e na obra impera a necessidade e a utilidade. Para Arendt, o trabalho representa a esfera biológica da vida e está associado à manutenção das necessidades vitais. A obra, por sua vez, representa a interferência "artificial" do homem na criação e manutenção de um mundo mais propício a sua sobrevivência; na obra impera a utilidade, cujo produto - assim como o produto do trabalho - é sempre um meio para determinado fim.

Essa breve comparação entre as três categorias que constituem a vita activa nos permite esclarecer e distinguir o que é próprio da ação: apenas a ação constitui o âmbito público; é ela quem permite o exercício da liberdade; e é ela quem dá sentido às nossas atividades.

No entanto, na tentativa de compreender a realidade moderna, Hannah Arendt percebe um cenário que se movimenta na direção contrária aos princípios de pluralidade e de liberdade. Um movimento, portanto, que mina as características mais fundamentais da esfera pública. Se ela estiver correta nos seus aspectos mais gerais, então isso deveria constituir tema de preocupação para todos nós. $O$ fato de que parece não haver uma ampla preocupação e debate sobre esse fenômeno pode ser um indício do quão contaminados estamos pelo cientificismo4. Com efeito, Arendt vê nas raízes do pensamento moderno cientificista uma "mola propulsora" para a despolitização. A política passa a ser concebida como um campo para a burocracia, a administração e a propaganda; avança uma concepção instrumental e técnica da política que afasta os indivíduos de sua construção.

\section{Emergência da modernidade, da ciência moderna e o abalo à esfera pública}

Segundo Hannah Arendt, podemos caracterizar a emergência da era moderna por meio de três grandes eventos:

\footnotetext{
${ }^{4}$ Até aqui, utilizei os termos "cientificismo" e "pensamento cientificista" sem qualquer esclarecimento sobre seu uso. Provavelmente não houve problemas em interpretá-lo. Mas minha utilização desses termos merece uma nota, primeiro, por não estar em Arendt; segundo, porque os utilizo com um sentido bem delimitado. Entendo por "cientificismo" uma concepção que tende a interpretar todos os fenômenos, incluindo a esfera pública, de um modo bastante peculiar. Trata-se de uma interpretação caracteristicamente moderna que remonta as tradições baconiana e cartesiana. O controle e a dominação da natureza - como objetivo último do fazer científico em Francis Bacon (1561-1626) - e a metafísica fisicalista de René Descartes (1596-1650) na qual os fenômenos devem ser investigados abstraindo-os de todo contexto (humano, social e ambiental) de modo a se desvendar suas leis subjacentes, expressas quantitativamente - possuem uma relação recíproca. As concepções baconiana e cartesiana se reforçam mutuamente. Se o progresso humano é identificado com o máximo controle da natureza (Bacon) e se a ciência deve servir ao progresso humano, então a ciência deve ser estruturada unicamente por abordagens fisicalistas (Descartes). Reciprocamente, se a ciência sobrevaloriza as abordagens fisicalistas (Descartes), então favorecerá a perspectiva de valor do máximo controle da natureza (Bacon). Esta interpretação é realizada pelo filósofo da ciência Hugh Lacey (1999; 2008). O meu ponto aqui é a transposição desta concepção (fisicalista/descontextualizadora e instrumental) para a esfera pública. Entendo por "pensamento cientificista" a concepção que interpreta desta forma peculiar não apenas a ciência, mas a ampla gama de fenômenos da vida humana, incluindo a esfera pública.
}

REIS, Claudio Ricardo Martins dos. Pensamento científico moderno e abalo à esfera pública: uma reflexão com base em Hannah Arendt. Griot : Revista de Filosofia, Amargosa/Bahia, v.17, n.1, p.304-314, junho/2018. 
A descoberta da América e a subsequente exploração de toda a Terra; a Reforma, que, expropriando as propriedades eclesiásticas e monásticas, desencadeou o duplo processo de expropriação individual e acúmulo de riqueza social; e a invenção do telescópio, ensejando o desenvolvimento de uma nova ciência que considera a natureza da Terra do ponto de vista do universo. (ARENDT, 2010, p. 309)

Arendt nos diz que embora aos olhos daqueles contemporâneos o evento mais espetacular deva ter sido a "descoberta" dos continentes e o evento mais inquietante a cisão da cristandade ocidental devido à Reforma e o seu desafio à ortodoxia, o mais importante do ponto de vista histórico - capaz de eclipsar não só o alargamento da superfície da Terra, mas também o processo econômico de acumulação - foi a fabricação e utilização do telescópio, que representa a base onde se desenvolveu o pensamento científico moderno e seu posterior avanço para todos os domínios da vida. Porém, Arendt faz notar que esses três eventos bastante distintos, ao se desenvolverem, apresentaram uma consequência comum e preocupante: a alienação do mundo.

\section{"Descoberta" da América e alienação do mundo}

A exploração da Terra pelas navegações pode parecer, à primeira vista, um meio capaz de aproximar os homens do mundo; seu efeito, porém, foi exatamente o inverso. Os circunavegadores lançaram-se ao mar para ampliar a Terra, mas acabaram por reduzi-la ao "globo". O que era tido como imenso passa a ser mensurável e estar ao alcance da mão.

Antes que soubéssemos como contornar a Terra, como circunscrever em dias e horas a esfera da morada humana, já havíamos trazido o globo à nossa sala de estar, para tocá-lo com as mãos e girá-lo ante nossos olhos. (ARENDT, 2010, p. 312)

Segundo Arendt, essa aproximação simbólica provoca um distanciamento real dos homens em relação ao ambiente - o mundo ou a Terra. Se os homens poderão agora melhor investigar e medir, pouco espaço mundano e terrestre lhes restará.

\section{Reforma e alienação do mundo}

A Reforma, um evento completamente diferente, teria nos colocado ante um fenômeno semelhante de alienação. Segundo Arendt, Max Weber foi quem identificou esse fenômeno, denominando-o "ascetismo intramundano" (innerworldly), que teria sido a fonte da mentalidade capitalista. Essa alienação intramundana é interpretada por Arendt não apenas como a fonte de uma nova moralidade, resultante das tentativas de Lutero e Calvino de restaurar a inabalável além-mundanidade da fé cristã (interpretação que é própria de Weber), mas também como a fonte da "expropriação do campesinato, consequência imprevista pela expropriação da Igreja e, como tal, o fator isolado mais importante no colapso do sistema feudal" (ARENDT, 2010, p. 313).

Ainda assim, é surpreendente que Weber não tenha deixado escapar de sua análise o papel que essa alienação do mundo exerceu para o desenvolvimento do processo de apropriação e acumulação de capital. Arendt destaca:

A grandeza da descoberta de Weber quanto às origens do capitalismo reside precisamente em sua demonstração de que é possível haver uma enorme

REIS, Claudio Ricardo Martins dos. Pensamento científico moderno e abalo à esfera pública: uma reflexão com base em Hannah Arendt. Griot : Revista de Filosofia, Amargosa/Bahia, v.17, n.1, p.304-314, junho/2018. 
atividade estritamente humana sem que haja qualquer cuidado ou deleite com o mundo, uma atividade cuja motivação mais profunda é, ao contrário, a preocupação e o cuidado com o si-mesmo. (ARENDT, 2010, p. 316)

\section{Ciência moderna e alienação do mundo}

A invenção e utilização do telescópio representa, para Arendt, outra forma de alienação da Terra. Como já dito, entre os três eventos mencionados, esse seria o mais crucial para a formação do pensamento moderno, além de ser o mais preocupante por demonstrar a capacidade humana para a criação e destruição da natureza.

Esse evento tem características centrais. Primeiramente, a ciência passa a ter um caráter universal, quebrando a dicotomia entre o céu e a Terra. Se antes céu e Terra eram considerados campos distintos, governados por forças independentes - o que justificava a distinção entre uma física celeste e uma física terrestre -, com Galileu céu e Terra são unificados. Mais que isso. A revolução copernicana representa uma inversão do ponto de referência: leva o "ponto arquimediano" para longe da Terra. A derrubada do geocentrismo ptolomaico e a introdução do heliocentrismo retira a qualidade especial e única da Terra e a coloca como um planeta entre outros. A "física terrestre" passa a ser apenas uma aplicação da "física celeste", consideravelmente modificada pela nova forma de investigação científica. Além de uma unificação, portanto, a Terra passa a ter sua importância explicativa subsumida a leis universais. De fato, o fenômeno é mais bem descrito como uma redução explicativa do que uma unificação.

O segundo impacto desse evento deve-se também - e crucialmente - a que o conhecimento daí gerado não é produto da especulação, da introspecção ou da mera observação dos sentidos, mas de uma ampliação antes inimaginável desses sentidos pela fabricação de um instrumento.

Não foi a razão, mas um instrumento feito pela mão do homem, o telescópio, que realmente mudou a concepção física do mundo; o que os levou ao novo conhecimento não foi a contemplação, nem a observação, nem a especulação, mas a ativa interferência do homo faber, da atividade de fazer e de fabricar [making and fabricating]. (ARENDT, 2010, p. 342)

O conhecimento se mostra não como resultado direto da razão ou dos sentidos, mas como produto da criação humana de um ambiente a ser observado. Além disso, traz consigo a possibilidade de concretização de um ideal. A especulação e a imaginação eram formas de pensamento incapazes de desvelar os "segredos do universo". Elas podiam ser tomadas como doutrinas ou como hipóteses, mas sem qualquer possibilidade de comprovação. É com o aparecimento de Galileu e o uso do telescópio que, pela primeira vez, isso se tona possível.

O que Galileu fez e que ninguém havia feito antes foi usar o telescópio de tal modo que os segredos do universo foram fornecidos à cognição humana "com a certeza da percepção sensorial", isto é, colocou ao alcance de uma criatura presa à Terra e de seus sentidos presos ao corpo aquilo que parecia estar para sempre além de suas capacidades - na melhor das hipóteses, estava aberto às incertezas da especulação e da imaginação. (ARENDT, 2010, p. 324)

Porém, é característico que nesse desenvolvimento "tanto o desespero quanto o triunfo são inerentes" (Arendt, 2010, p. 326). O desespero é primeiramente filosófico e forma a base da filosofia moderna, que tem na dúvida seu aspecto mais fundamental e

REIS, Claudio Ricardo Martins dos. Pensamento científico moderno e abalo à esfera pública: uma reflexão com base em Hannah Arendt. Griot : Revista de Filosofia, Amargosa/Bahia, v.17, n.1, p.304-314, junho/2018. 
motivador. Descartes, como o pai dessa nova filosofia, pretende construir um conhecimento infalível e, para isso, passa a conceber os sentidos e o mundo com profunda desconfiança. A filosofia se virará para o "eu" interior, tendo no racionalismo e no subjetivismo suas principais formas de expressão. Ante o triunfo da ciência moderna, a filosofia responde com a dúvida e o desespero. Mas esse sentimento não se limitou aos filósofos; tomou eco em vários setores da população e, a partir do século $\mathrm{XX}$, entre os próprios cientistas. Como Arendt afirma:

$O$ advento das ciências naturais é creditado a um aumento demonstrável e cada vez mais célere do poder e do conhecimento humanos. [...] No entanto, com igual razão, o mesmo fenômeno foi responsabilizado pelo não menos demonstrável aumento do desespero humano, ou pelo niilismo especificamente moderno que se propagou para setores cada vez maiores da população, do qual o aspecto mais significativo talvez seja o de que já não poupa os próprios cientistas, cujo fundamentado otimismo, no século XIX, ainda foi capaz de enfrentar o igualmente justificável pessimismo de pensadores e poetas. (ARENDT, 2010, p. 325)

Em terceiro lugar, é importante observar que o controle da natureza através da fabricação de instrumentos materiais e da experimentação, subsumidos a instrumentos mentais, como o raciocínio lógico-matemático e a quantificação, passam a ser centrais para a investigação científica moderna. Hannah Arendt dirá que:

\begin{abstract}
Ainda mais significativo [...] foi o fato de que o novo instrumento mental, que, sob esse aspecto, era ainda mais novo e mais importante que todos os instrumentos científicos que ajudou a inventar, abriu o caminho para uma forma inteiramente inédita de abordar a natureza e de se aproximar dela no experimento. No experimento, o homem [...] colocou a natureza sob as condições de sua própria mente. (ARENDT, 2010, p. 331)
\end{abstract}

Previsão e possibilidade de controle dos fenômenos passam a ser a principal busca da ciência, e o raciocínio enquanto "cálculo de consequências" se torna o modelo de pensamento, inclusive para a filosofia moderna. "A razão, tanto em Descartes quanto em Hobbes, torna-se 'cálculo de consequências', a faculdade de deduzir e concluir, isto é, um processo que o homem pode, a qualquer momento, desencadear dentro de si mesmo." (ARENDT, 2010, p. 354).

\title{
Abalo à esfera pública
}

A ideia de que o novo conhecimento está subsumido a uma lógica ordenada pela mente humana é crucial para Arendt, porque isso constituiria tanto um fundamento para a alienação da Terra quanto uma consequência nefasta para a política. Ela dirá, por exemplo, que "os eventos só poderiam ser salvos [no sentido de poderem ser explicados pela ciência] na medida em que pudessem ser reduzidos a uma ordem matemática" (Arendt, 2010, p. 332). Para Arendt, essa forma de pensar produz uma alienação da Terra e, transposta para a política, invalida sua construção coletiva. A própria ideia de que a política deva estar sujeita a um método único e independente da pluralidade dos indivíduos é, por si só, uma certificação de sua morte.

Essa transformação característica do pensamento moderno torna a esfera pública um espaço em que a ação é substituída por regras de conduta. Feitos e eventos, no sentido em que Arendt lhes dá, tornam-se cada vez mais raros, pois fogem às expectativas

REIS, Claudio Ricardo Martins dos. Pensamento científico moderno e abalo à esfera pública: uma reflexão com base em Hannah Arendt. Griot : Revista de Filosofia, Amargosa/Bahia, v.17, n.1, p.304-314, junho/2018. 
impostas aos indivíduos e aos padrões de comportamento a que eles deveriam se adequar. Isso produz uma sociedade cada vez mais conformista e uniforme. Esse ideal de prever comportamentos e ações é incorporado inclusive pelas ciências humanas. Para Arendt, isso explicaria a emergência do behaviorismo na psicologia e na sociologia, além da consolidação da estatística como seu principal instrumento.

No entanto, é justamente devido à imprevisibilidade que os homens que agem podem se considerar livres. É a espontaneidade no âmbito da ação o que garante a liberdade humana. Arendt é taxativa: "a espécie humana é distinta de todas as espécies animais não apenas pela sua posse da fala e da razão, mas porque suas faculdades são capazes de desenvolvimento indeterminável" (Arendt, 1992, p. 59, tradução livre).

Quando a espontaneidade e seu caráter plural estão ausentes da esfera pública - o que é característico dos totalitarismos e das sociedades de massa - a política, no sentido autêntico considerado por Arendt, desaparece. É por isso que a autora trata essas experiências não como formas distintas de fazer política, mas como a própria negação da política. São movimentos profundamente ideológicos, que procuram se justificar com base em seus próprios pressupostos e alheios a toda a realidade. Como afirma Casseti (2011):

[...] sem nenhum tipo de ação coletiva perde-se a política - ou seja, o espaço por excelência para o desenvolvimento da liberdade humana. De acordo com Arendt, o oposto de um governo ideológico é a própria política: isto é, a existência de um corpo de cidadãos que interagem e revelam publicamente seus pontos de vistas e opiniões sobre a realidade, constituindo um mundo em comum entre eles, no qual a pluralidade é a sua condição e a liberdade seu significado. (CASSETI, 2011, p. 23)

É crucial para Arendt, então, que além de conformar um campo próprio para o pensamento científico, essa nova forma de pensar, especificamente moderna, alastra-se para os mais diversos domínios da atividade humana. Quando recai sobre a ação, mina a dinâmica da esfera pública, constituindo um obstáculo para a efetivação da pluralidade e da espontaneidade humanas. Em outros termos, essa mentalidade vai à contramão da dinâmica de uma política autêntica, porque a encara como um processo eminentemente técnico, administrativo, determinista e previsível. Não há espaço para a construção coletiva do que não está dado; não há sequer o espaço em comum para as múltiplas perspectivas entrarem em debate, refletirem e deliberarem. É nesse sentido que o pensamento cientificista nega a possibilidade da política.

Vimos que em Arendt a política não é um assunto, mas uma atividade. Essa atividade é caracterizada pela ação. Dessa forma, quando a política é contaminada pelo cientificismo - o que acaba por impossibilitar a ação - ela deixa de ser política. Ao esmagar o âmbito público, apaga o que é eminentemente humano e que dá sentido a nossas vidas.

A emergência do pensamento científico moderno, caracterizado pela lógica do homo faber, gerou, portanto, consequências tanto epistemológicas - no modo de produção do conhecimento, como a sobrevalorização da predição e do controle - quanto políticas extraindo seu caráter mais fundamental e seu potencial transformador.

\section{Considerações finais}

Vimos como Hannah Arendt caracteriza a modernidade e como esta é capaz de produzir uma alienação do mundo; vimos ainda como a emergência e consolidação do

REIS, Claudio Ricardo Martins dos. Pensamento científico moderno e abalo à esfera pública: uma reflexão com base em Hannah 
pensamento científico moderno impacta nas atividades humanas, em especial na esfera pública; e vimos como o cientificismo é capaz de minar a política autêntica.

Retomando o desenvolvimento do artigo, seriam três os eventos fundamentais para o início da era moderna. Arendt se refere à exploração dos continentes e seu efeito em trazer o imensurável ao alcance das mãos; à Reforma, sua nova moralidade e sua relação entre a expropriação eclesiástica e a expropriação dos camponeses; e a invenção e utilização do telescópio, que fez emergir uma ciência universal ao mesmo tempo em que contribuiu para a alienação do homem da Terra.

Esses eventos bastante distintos tem em comum o fato de que formam a base para uma alienação do mundo. Se os circunavegadores desejavam explorar a Terra, o efeito gerado foi tê-la como um "globo" dentro de nossas casas. Se a Reforma foi uma crítica à ortodoxia religiosa, também colocou os fundamentos para uma nova economia baseada na apropriação e acúmulo de capital. Se a ciência moderna produziu uma nova forma de conhecimento e um novo critério de avaliação - o sucesso prático - também gerou preocupação por suas aplicações tecnológicas e pela contaminação da política com seu método.

O pensamento cientificista, produto e produtor da modernidade, gerou uma nova forma de conhecimento, mas também uma nova forma de conceber o âmbito público. No campo epistemológico, trouxe a centralidade do experimento, dos instrumentos de medida e do raciocínio matemático e quantificador. Associando essas três características, podemos dizer que a ciência moderna realça a lógica do homo faber, dado que produz um conhecimento que é dependente da fabricação de instrumentos e do enquadramento da natureza aos moldes da mente humana. $O$ conhecimento produzido é consequência da criação de um ambiente a ser observado, e o que se apreende dele é o que pode ser captado em modelos previamente pensados. Aplica-se, dessa forma, um raciocínio que envolve direta e unicamente um "cálculo de consequências".

Vimos como essa lógica do homo faber, ao invadir o âmbito público, acaba com a possibilidade da política. Para Arendt, a esfera pública é fundamentalmente o espaço para a ação. A ação é possível quando os indivíduos, em sua pluralidade e singularidade, constroem um ambiente comum para refletir, debater e deliberar conjunta e autonomamente. É condição para a ação a imprevisibilidade. Por isso toda imposição de padrões de comportamento, regras de conduta e formas prévias de interação constituem movimentos contrários ao sentido mais fundamental e autêntico da política. Governos totalitários e sociedade de consumo são exemplos extremos e reais de como liquidar com o âmbito público através da lógica do homo faber e da contaminação pelo cientificismo em todas as esferas da vida humana.

Nesse contexto, aquilo que Hannah Arendt concebe como ação, a atividade humana que é por excelência produtora de sentido, perde lugar para a obra/fabricação. Se a crítica mais fundamental de Arendt ao pensamento ocidental da antiguidade era de que a vita contemplativa estava hierarquicamente acima da vita activa, sua crítica à modernidade é de que, apesar de ter havido uma inversão na hierarquia, o que efetivamente está acima é o trabalho e a obra, não a ação. Contudo, a vita activa é constituída por essas três atividades conjuntamente. Se não há espaço para a ação, não há possibilidade para a manifestação da liberdade humana, de sua pluralidade e de sua espontaneidade. Além disso, não é possível dar sentido a qualquer outra atividade. $O$ trabalho e a obra, mesmo que amplamente exercidos, não são capazes de dar significado a nossas vidas:

REIS, Claudio Ricardo Martins dos. Pensamento científico moderno e abalo à esfera pública: uma reflexão com base em Hannah Arendt. Griot : Revista de Filosofia, Amargosa/Bahia, v.17, n.1, p.304-314, junho/2018. 
[...] se a ação política for decidida a partir dos critérios do homo faber, isto é, se ela for reduzida à razão matemática, somos obrigados a concordar que não existe qualquer diferença na maneira como os homens pensam ou agem. Tanto a ação como o pensamento individual não teriam relevância alguma no espaço público, pois o único caminho possível para a política estaria na sua redução à lógica da fabricação, ao "cálculo de consequências". (DEINA \& KOMINEK, 2016, p. 1112)

Hannah Arendt apresenta esse diagnóstico fortemente preocupante da sociedade moderna e contemporânea, com muito mais profundidade, diga-se de passagem, do que eu pude trazer nestas poucas páginas. Em todo caso, o desafio está posto. Cabe a nós repensar a atualidade e agir sobre ela. Não temos um método a priori para alcançar o ideal de esfera pública caracterizado por Arendt. Nem teria como. Esse ideal explicitamente invalida sua estruturação por um método único e independente dos indivíduos. É por isso que nossa reflexão não pode estar apartada da realidade. O que nos cabe é refletir enquanto atuamos. Mas como solucionar esse impasse? Precisamos resgatar o sentido autêntico da política, o que requer a criação de ambientes propícios em que ela possa florescer. Embora não tenhamos as respostas definitivas, podemos começar criando espaços para o agir comunicativo e a radicalização da democracia. O desafio não é pequeno: envolve reestabelecer a ação enquanto atividade caracteristicamente humana e transformar a liberdade e a pluralidade, de meras palavras com sentido abstrato, em valores amplamente incorporados e efetivados na esfera pública. 


\section{Referências bibliográficas}

ARENDT, Hannah. Lectures on Kant's political philosophy. Chicago: The University of Chicago Press, 1992.

. Entre o passado e o futuro. Tradução de Mauro Barbosa. São Paulo: Editora Perspectiva, 2005. . A Condição Humana. Tradução de Roberto Raposo. Rio de Janeiro: Forense Universitária, 2010.

CASSÉTE, Mariah. A Ciência e a Sociedade Moderna: uma visão da teoria política de Hannah Arendt. In: Anais do XV Congresso Brasileiro de Sociologia, Curitiba, 2011. p. 125.

DEINA, Wanderley José \& KOMINEK, Andreia Maila. Sobre o sentido político da ciência e da tecnologia em Hannah Arendt. In: Anais da XI Jornadas latino-americanas de estudos sociais da ciência e da tecnologia, Curitiba, 2016. p. 1-12.

D'ENTREVES, Maurizio Passerin. Hannah Arendt. In: The Stanford Encyclopedia of Philosophy. Edição de inverno de 2016. Disponível em:

$<$ https://plato.stanford.edu/archives/win2016/entries/arendt/>. Acesso em: 07.02.2018.

KUHN, Thomas. The structure of scientific revolutions. Chicago: University of Chicago Press, 1962.

LACEY, Hugh. Is Science Value Free? Values and scientific understanding. London:

Routledge, 1999.

. Entendimento científico e controle da natureza. In: LACEY, Hugh. Valores e atividade científica 1. São Paulo: Associação Filosófica Scientiae Studia/Editora 34, 2008. p. 153-188.

\section{Agradecimentos:}

Gostaria de agradecer à CAPES pela bolsa de pesquisa e ao Nuno M. P. Castanheira pelas contribuições dadas a este trabalho.

Autor(a) para correspondência: Claudio Ricardo Martins dos Reis, Universidade Federal do Rio Grande do Sul, Instituto de Filosofia e Ciencias Humanas, Av. Bento Gonçalves, 9500, CEP 91509-900, Porto Alegre RS, Brasil. claudiormreis@gmail.com 